\title{
LA HUELGA DE BRAZOS CAIDOS Y GUERRA CIVIL DE 1948
}

Manuel Calderón H.

\section{LA CUESTION SOCIAL DE LOS AÑOS 40.}

La década de los años 40 puede ser valorada como una, o la más importante del siglo XX que se vivió en Costa Rica. Su importancia política radica en que en ella, fenece la república liberal y sus prácticas sociales, a la vez se crean las condiciones necesarias para el desarrollo del "Estado del Bienestar Costarricense". Por eso es la década de los grandes cambios y transformaciones, indiscutiblemente marcan el quehacer social de la segunda mitad del siglo XX.

Es el periodo más rico de la historia republicana que viven los costarricenses en cuanto a situaciones políticas. Es una década de profundas contradicciones sociales, las cuáles venían acumulándose desde el siglo XIX. Es un momento histórico en que diferentes sectores sociales deciden ser dueños de su propio destino, por eso, es la década del conflicto y cambio social. Es el tiempo de las alianzas y las confabulaciones, los alineamientos de clase, es la época de los frentes populares, marcados por la lucha antifascista. Es el momento en que amplios sectores sociales de costarricenses cansados de vivir en el desamparo legal con gran incertidumbre; mientras la clase dominante, degustaba del banquete social celosamente cuidado por el estado liberal. Es la época en que se manifiestan de manera beligerante nuevos actores sociales que habían surgido políticamente en las luchas contra la dictadura de los tinocos.

La década de los 40 significa el surgimiento de nuevos planteamientos por parte de actores pequeño burgueses dispuestos a disputarle el espacio político a las viejas fuerzas salidas del proyecto liberal 
y constituidas en burguesía agraria; a la vez inician la confrontación con el partido comunista. La pequeña burguesía urbana que surge con grandes brios en la lucha por lograr un espacio en el añejo quehacer político basándose en nuevos planteamientos, amparados en la social democracia.

El dinamismo de la década de los 40 que se expresa en las transformaciones que sufre el estado a raíz del empuje político que impulsan amplios sectores sociales; acción que fue leída correctamente por los políticos del momento. Es así como las luchas se van concretizándose en nuevas relaciones sociales entre el trabajo y el capital, legalizadas en la constitución de 1871, al crearse el capítulo de las garantías sociales.

Los logros de la década de los 40 abrieron el camino para la modernización y el sostén de las bases políticas que los costarricenses han vivido en los últimos 50 años.

No es casual por lo señalado que dicha década, posiblemente es la más estudiada en la historia de Costa Rica. Es el período que más ha llamado la atención de estudiosos en el campo de las ciencias sociales nacionales y extranjeros. Por eso no extraña encontrar estudios de: sociólogos, politólogos, abogados, políticos, historiadores. Trabajos que van desde vulgares panfletos, ensayos, libros, productos de investigaciones de grado y postgrado; los cuáles, abordan la problemática de la década desde diversos ángulos tanto teóricos, metodológicos y hasta ideológicos.

\section{BALANCE PARCIAL DEL ESTADO DE LA CUESTION}

No pretendemos hacer una presentación de la producción más significativa sobre esta década; el objetivo es evidenciar la pertinencia de ahondar en una situación particular de grandes consecuencias en los sucesos del 48. 
Llama la atención que en algunos de los estudios más significativos de la época el caso de la huelga de brazos caídos recibió un tratamiento ligeramente marginal, a pesar de lo determinante que fue esta huelga en la guerra civil. Lo anterior puede ser constatado a partir de la siguiente exposición. Manuel Rojas Bolaños en su estudio (1) le dedica a la huelga muy poco espacio y su análisis se limita a dar una descripción del hecho propiamente. De igual forma John Patrick Bell en su investigación (2) le dedica 6 páginas, presentando lo sucedido en términos muy generales y sumando la huelga a los restantes hechos que surgieron en el conflicto. Don Eugenio Rodríguez Vega en la obra (3), no varía lo realizado por lo anteriores autores. Hace una descripción general de lo acontecido sin reparar en los efectos posteriores de la huelga.

El estudio de Oscar Aguilar B (4); en este caso, la huelga recibe un tratamiento de mayor profundidad y extensión pero termina desapareciendo en el análisis general de la problemática estudiada. La obra, Urnas de lo Inesperado (5) de reciente publicación, de los autores Iván Molina J y Fabrice Lehoucq; excelente obra sobre el fraude electoral entre 1901 y 1948; estos le dedican unos cuantos párrafos a la huelga, situación razonable dado que el objeto de estudio es muy claro: el fraude. Una interesante síntesis de la época de los 40 es el estudio de Victor Hugo Acuña (6), eso sí, el tratamiento que le da a la huelga es bastante general finalmente podemos señalar el trabajo de Fabrice Lehoucq (7), en lo relacionado a la huelga se limita solamente a citarla.

Como se ha constatado, el tratamiento dado a la citada huelga ha sido marginal; de inmediato salta la duda es importante dedicarle nuevos esfuerzos?. La respuesta es sí, ya que la huelga significa la coyuntura necesaria que le va a permitir a una fuerza política minoritaria como es el grupo social demócrata asumir nuevas posiciones y espacios políticos que 
le permiten recomponer las fuerzas al interior del grupo opositor y a partir de ese momento acceder al poder, una vez finalizada la guerra civil del 48.

\section{SITUACION POLITICA EN 1947}

La lucha por el poder político a mediados de 1947, aparentemente se había "definido" al establecerse los dos candidatos que lucharían por la presidencia de la república: Rafael Angel Calderón Guardia por el oficialismo y Otilio Ulate Blanco por la oposición. Estos dos candidatos, se presentan al electorado en un ambiente político de gran violencia, cargado de temores y resentimientos; particularmente, los temores y resentimientos son las aguas en que navegaba la oposición. Esta conducta se debe a: el temor a un fraude electoral sentimiento que embargaba a toda la oposición. Los resentimientos y frustración fundamentalmente enquistados en el grupo social demócrata en alianza con una oscura oposición; sobresalía entre los social demócratas José Figueres F, quien no olvidaba el exilio sufrido en el gobierno de Calderón Guardia (1940-1944) y menos la derrota del 13 de febrero de 1947 en la convención de oposición en donde sale ganador Otilio Ulate.

Con la derrota a Figueres Ferrer se le cerraba el paso a los jóvenes que habían fundado el Centro de Estudios para Problemas Nacionales a inicios de los 40. Para la tendencia social demócrata la situación era oscura y complicada pues realmente a su candidato la habían "barrido". El cálculo electoral de aliarse con una oposición conservadora intransigente y prepotente de poco les había servido. Eso sí, la derrota en la convención fortaleció otras tesis: el guerrerismo, postura política que desde tiempos atrás uno de los líderes social demócratas como José Figueres F. (8) comentaba a los cuatro vientos. La oposición guerrerista también es compartida por John Patrick Bell, quien sostiene : 
“El terrorismo comenzó en 1945 pero no fue un asunto de gravedad sino hasta fines de 1946, cuando la casa de Manuel Mora fue parcialmente destruida con dinamita.... Células organizadas del partido social demócrata llevaban a cabo una campaña sistemática de subersión (9).”

El grupo social demócrata con la derrota electoral inicia la ruta que lo alejaría del ámbito político electoral para acercarse al choque y a la confrontación, como única salida al conflicto político que se vivía desde: la promulgación de las garantías sociales y la alianza calderocomunista.

Los socialdemócratas tenían amplio conocimiento que al interior de la oposición, existían grupos sociales dispuestos a enfrentarlos en el momento oportuno. También sabían que la alianza con la oposición era un asunto coyuntural dados los proyectos políticos por los cuáles luchaban. La realidad política y la situación precaria que vivían los social demócratas en el seno de la oposición más la capacidad de análisis de algunos de ellos: Rodrigo Facio, Eloy Morua, Carlos Monge..., los hacen ver la necesidad de dar un golpe de timón en la situación social y la dinámica política, pues era necesario asumir un mayor protagonismo en la campaña que significara réditos políticos, o bien alterando las reglas del juego en este caso las leyes electorales.

Cambiar las leyes electorales por lo siguiente: Primero en la década de los 40 el sistema electoral se ve sometido a una fuerte campaña de desprestigio por parte de los derrotados en las elecciones presidenciales de 1944 y las de 1946 para diputados, alegando grandes fraudes (10) hoy se sabe que los fraudes se daban desde fines del siglo XIX, asunto que no es extraño en el siglo siguiente ya que también se ejecutaban; la realidad de los famosos fraudes es que si bien es cierto se daban el porcentaje 
fraudulento no alteraba el resultado final por lo tanto no eran decisivos (11).

Segundo, el conflicto social suscitado al calor de las garantías sociales y de la alianza calderocomunista, ambos hechos de profundos efectos en la sociedad costarricense al cambiar las reglas del juego liberal que regían las relaciones trabajo-capital. Esta particularidad no se le ubicó en la verdadera realidad por razones ideológicas al suplirse el conflicto de las garantías sociales como asuntos meramente electorales, de esta manera los perjudicados con las garantías sociales resumen el conflicto social a una cuestión electoral cuando en realidad las garantías sociales los había perjudicado, al alterar las reglas de reproducción de capital. Es así como los social demócratas ante su desastre electoral, de manera oportunista se aprovechan del desprestigio del sistema de elecciones que desde tiempos atrás se venía desarrollando con tal precisión que para 1947, era una verdad absoluta y por lo tanto las posibilidades de fraude eran reales, por eso cualquier lucha en pos de modificar las leyes electorales era una batalla posible.

Así las cosas el camino a seguir es la provocación al gobierno de Teodoro Picado, "Nuestro partido social demócrata, que es el grupo radical en cuanto se refiere a métodos de lucha ha venido insistiendo hasta la necedad - en público y privado - para que se reorganicen sin más dilatoria grupos de resistencia" (12). La oportunidad había que construirla, Cartago es el lugar indicado, pues en esa provincia "células organizadas del partido social demócrata llevaban a cabo una campaña sistemática" (13). Efectivamente, el 19 de julio de 1947 por la noche se organizó una manifestación de la oposición que terminó en un zafarrancho cuando la policía intervino ante la provocación de manifestantes con saldo de heridos, gases lacrimógenos y detenidos. Lo sucedido en Cartago, vienen a ser la 
oportunidad de oro que abre los espacios a la tesis de José Figueres: la única solución al conflicto es la fuerza. (14)

\section{LA HUELGA ACTORES SOCIALES Y LOS MEDIOS DE COMUNICACIÓN}

Los sucesos de Cartago dados el 19 de julio, son el detonante para que el siguiente lunes 21 se declare la huelga en altas horas de la noche, aún cuando Otilio Ulate no estaba muy convencido de tal acto, pues en horas de la mañana había expresado: "Puede ser más eficaz promover para dentro de tres o cuatro días un gran movimiento nacional de desobediencia y brazos caídos"(15).

Ese mismo lunes por la tarde, el secretario del "Partido" de la oposición Sr. Mario Echandi J.: "Convocó con carácter de urgente a los comités directivos de la oposición"(16) En las horas de noche se concreta la convocatoria, en donde el Sr. Ulate Blanco de nuevo opina: "la huelga no tiene carácter revolucionario es pacífica y ordenadamente"(17). La conducta de cautela y mesura expresada por Ulate desesperó a los social demócratas, provocando en sus delegados: el profesor Carlos Monge Alfaro y el Lic. Eloy Morúa: "se pronunciaron muy airadamente y le hicieran cargos a la dirección oposicionista por falta de organización”(18). La intervención de Monge Alfaro patentiza los intereses de su agrupación al interior de la agrupación.

Dada la situación de descontento reinante entre los reunidos se da la declaratoria de huelga, a avanzadas horas de la noche. Iniciándose así un paro de actividades económicas de carácter privado, con la participación de: la banca privada; las empresas comerciales más importantes ("boticas", almacenes de abarrotes, tienda de ropa, carnicerías, empleados estatales). El movimiento se desarrolla más allá del Valle Central según se desprende 
de la información periodística. La huelga involucra a los medios de comunicación masiva quienes se dividen en dos bandos: los oficialista y la oposición. La Universidad Costa Rica participa activamente de estos actos(19). "El país, pues, entró en un estado de paralización total con contadas excepciones ...estos establecimiento en conjunto suman cuatro o cinco pulperías”(20) El objetivo general de huelga es: “...no siendo la huelga un movimiento revolucionario, en cuanto no más, se obtuviera las garantías de libertad electoral por las que se lucha cesaría todo el movimiento cívico y todos retornarían a las actividades normales"(21).

El avance de los días fortalecía la huelga a pesar de los esfuerzos del Gobierno, lo anterior hace que el costo político para el Calderonismo crezca mientras que los social demócratas disfrutaban del protagonismo. Por ejemplo la breve detención de Rodrigo Facio, oportunidad bien aprovechada para que con gran estridencia, los medios de información al servicio de la oposición lanzara suficientemente lodo al gobierno y abonaran el lego del señor Facio: "esta mañana, encontrándome con tres amigos en la puerta de mi oficina fuí detenido por un policía, quien me condujo junto con ellos a la estación de policías, procedieron luego a inventar un truculento parte en nuestra contra"(22). Eses es parte del telegrama que le envió el señor Facio Brenes al presidente Teodoro Picado.

El diario Costa Rica, al servicio de la oposición informa el viernes 29 de junio; “...fueron puestos en libertad Daniel Oduber y Gonzalo Facio, a quienes las autoridades apresaron el domingo en la noche"(23). Las noticias en torno al presbítero Benjamín Nuñez son notorias y abundantes durante el período de huelga a quién se le calificaba como dirigente obrero católico.

La huelga no se enfriaba gracias a la leña que constantemente producía la prensa y la radio pues estos, juegan un papel beligerante caracterizados por un burdo amarillismo como método de acción. Por 
ejemplo el diario Costa Rica propiedad de Otilio Ulate se refiere en grandes titulares a lo sucedido en Cartago.

"Numerosos heridos dejó la polícía al atacar la ciudadanía indefensa con ametralladoras, fusiles, pistolas y gases lacrimógenos"(24).

El 25 de julio el mismo diario informa: "saqueado Cartago ayer en la madrugada por los comunistas"(25). La guerra fría condimentaba sin duda alguna el conflicto social. La prensa de oposición se dió a la tarea de sacara los demonios xenofóbicos, cuando identifican a emisoras de radio pro gobierno. "La Voz de la Víctor y Radio City, cuyos propietarios son extranjeros que con ningún derecho se inmiscuyen en los asuntos de interés colectivo nacional”(26); “...una intolerable actitud de un comerciante extranjero. La Jardinería Pujol va a la lista negra de los enemigos de la República"(27). los periódicos de oposición, hasta llegaron a publicar lista negras de empresas que se oponían a la huelga. En el bando contrario, no fue muy diferente la situación, en el sobresalía la tribuna, haciendo esfuerzos por minimizar la huelga y los actos provocativos de la oposición se ignoraban o se descalifican con particular estilo. El periódico La Nación fiel aún estilo histórico periodístico no cesaba de atacar al Calderonismo, a los comunistas y al gobierno, haciendo de la guerra fría su pasión y el combustible que la movía en su accionar ideológico. Realmente en esta coyuntura en el ambiente flotaba la mentira, la infamia y la confabulación ingredientes históricos de la política costarricenses.

La prolongación de la huelga incide en un altísimos costo política para el calderonismo y el mismo gobierno no quedando otra alternativa que "negociar" el levantamiento de ella.

\section{NEGOCIACIÓN Y CONSTITUCIONALIDAD}


El 3 de agosto de 1947 se llegó al acuerdo de levantar la huelga, al firmarse por el gobierno y el Comité que dirigía el movimiento huelguístico al acordarse una serie de transformaciones en las condiciones electorales. La oposición después de casi quince días de lucha en diferentes regiones del país en escenarios como las calles, la prensa y la radio habían logrado el objetivo planteado "garantías de interés electoral". Los acuerdos firmados son:

El compromiso de que personas de gran providad cívica ocuparían los puesto claves en los organismo electorales (28). El gobierno le entregó al Tribunal Electoral, (a la oposición) con tal de acabar con la huelga y los diputados gobiernistas se comprometían ha aceptar el fallo (sobre el resultados de las elecciones) (29). Semejante error político y violatorio al orden constitucional no es aceptado por loa comunistas que "se negaron a suscribir el acuerdo que puso fin a la huelga"(30).

) Se aceptaría como definitivo e inapelable la resolución que sobre las elecciones que durante el mes de febrero entrante emita el Tribunal Supremo de Elecciones (31)

El Presidente de la República y su secretario de seguridad pública entregarán en el término de 24 horas después de firmada la resolución, el control de las fuerzas públicas al ciudadano favorecido por la referida declaratoria de elección.

No se tomarán represalias algunas contra personas, funcionarios públicos, y empresas que participaron en el movimiento de huelga.

El acuerdo firmado, puso fin a la huelga pero éste, violentó la Constitución Política pues un movimiento de hecho la modificó en dos campos cardinales del quehacer costarricense: el relacionado a los asuntos electorales y el de seguridad, ya que con la firma del pacto el Señor Presidente renunciaba sin haber concluído su periódo presidencial al 
control de las fuerzas de seguridad según lo establecía la Carta Magna. Igualmente grave es la entrega a la oposición del Tribunal Electoral, acción que riñe con la Constitución. lo más sorprendente de este acuerdo es que a la Asamblea Legislativa se le desconoció como instancia deliberativa y legalmente constituida como la única con responsabilidad de poder modificar la Constitución Política. Posiblemente, nos encontramos con un "golpe de estado técnico". Sin embargo, los llamados a dictaminar sobre este golpe de estado son los constitucionalistas pues los historiadores no somos los más indicados en dar opiniones definitivas.

Evidentemente, los resultados políticos de la huelga favorecieron al grupo social demócrata: su protagonismo fue notorio en todo el movimiento; crearon las condiciones necesarias y el fortalecimiento de sus tesis guerreristas; se beneficiaron con los nuevos integrantes relacionados directamente con los asuntos electorales, por ejemplo, el director del Registro Electoral, don Benjamín Odio, “dejó la capital para unirse a las fuerzas de Figueres en el sur antes de que el Tribunal Electoral declarara vencedor a Ulate"(32). Como bien lo señala Iván Molina, la actuación del señor Odio es cuestionable por ser responsable del Registro Electoral instancia que cambió la geografía electoral: “el padrón electoral publicado poco antes de la elección de 1948 sobre valoró el tamaño del electorado en las provincias que predominaba el Ulatismo -Unión Nacional- (sobre todo en Alajuela y Cartago) y los sub valoró en las que era fuerte el Calderonismo - Republicano Nacional (en especial Puntarenas y Limón)"(33). En fin la huelga se constituyó en el primer acto de los sucesos que nos llevarían a la Guerra Civil del 1948 y al ascenso del poder del grupo social democráta. 


\section{CONCLUSIONES}

La Huelga de Brazos Caídos debe dimensionarse en el contexto de las luchas sociales emprendidas por sectores pequeños burgueses que se presentan de manera más efectiva en contra de la tiranía de los Tinoco: la década de los cuarenta es la concreción de dichos movimientos al abrir espacios en la arena política, permitiéndole asumir posiciones de gran relevancia y presencia nacional.

La huelga sirvió para fortalecer las tesis compulsivas hacia la toma del poder que al fin y a cabo fueron las que se impusieron.

\section{CITAS Y BIBLIOGRAFIA}

1. Rojas Bolaños Manuel. Lucha Social y Guerra Civil en Costa Rica. 1940-1948. San José, Editorial Alma Mater 1986, pags 140-141.

2. Patrick Bell John. Guerra Civil en Costa Rica. San José, Editorial Educa 1976, pags 136-139.

3. Eugenio Rodríguez Vega. De Calderón a Figueres. Costa Rica, Editorial UNED 1980, pags 151-160.

4. Aguilar Bulgarelli Oscar. Costa Rica y sus hechos Políticos de 1948. San José, Editorial Costa Rica 1993, pags 201-237.

5. Molina Jiménez Iván y Lehoucq Fabrice. Urnas de los Inesperado. Costa Rica, Editorial UCR 1999, pags 184.

6. Acuña Ortega Victor Hugo. Conflicto y Reforma en Costa Rica: 1940-1949. San José, Editorial UNED 1992. 
7. Lehoucq Fabrice. "Conflicto de Clases, Crisis Política y Destrucción de las Prácticas Democráticas". En Revista de Historia No.25 Enero - Junio Costa Rica 1992, pags 66-96.

8. Véase Acuña Ortega Ibidem.

9. Patrick Bell Ibiden, pags 134-135.

10.Iván Jiménez y Fabrice Lehoucq Ibidem, pags 167-179.

11.Ibiden pags 133-152.

12.Diario Públicado por Eugenio Rodríguez en: $\underline{\boldsymbol{D e} \text { Calderòn } \boldsymbol{a}}$ Figueres..., pag 166.

13._Patrick Bell Ibiden, pags 135.

14. Acuña Ortega, ob. cit. pág. 25

15. El Diario de Costa Rica, 23 de julio de 1947, pág. 1-6

16. Ibidem, pág. 1-6

17.Ibidem, pág. 1-6

18. Ibidem, pág. 1-6

19.Fumero Vargas Patricia

20.El Diario de Costa Rica, 25 de julio de 1947, página 1.

21.Primera Plana del 25 al 30 de julio de 1947, página 20

22.El Diario de Costa Rica, 25 de julio de 1947, página 1.

23.Ibidem, pág. 1

24.Ibidem, 22 de julio de 1947, pág. 1-6

25.Ibidem, 25 de julio de 1947, pág. 1

26.Ibidem, 25 de julio de 1947, pág. 1

27.Ibidem, 25 de julio de 1947, pág. 1

28.Primera Plana, 3 de agosto de 1937, pág. 20

29.Ibidem, pág. 20

30.Ibidem, pág. 20

31.Aguilar Bulgarelli Oscar. Ob. cit. pág 228 
32.Schifter Jacobo. La Fase Oculta de la Guerra Civil de Costa Rica. San José, Editorial EDUCA, 1981, pág. 80

33.Molina Jiménez Iván y Lehoucq Fabrice.Ob. cit. pags 173-184. 